\title{
Comparison of three different extraction methods for Turbellaria
}

\author{
Paul M. Martens \\ Department SBM, Limburgs Universitair Centrum, 3610 Diepenbeek, Belgium
}

\begin{abstract}
Three different extraction methods for Turbellaria were compared, 2 of which use living material. The first method is based on sea-water ice treatment (Uhlig-method), the second employs decantation of narcotized fauna ( $\mathrm{MgCl}_{2}$-method). The third method is the Barnett-method, performed on preserved material. Three series of 12 samples each were analysed quantitatively. Turbellaria were counted and identified to the order level. For the turbellarian population, as a whole, the numbers of individuals extracted alive (Uhlig- or $\mathrm{MgCl}_{2}$-method) was less than $50 \%$ of the number extracted from the preserved samples (Barnett-method). Differences between Uhlig-method and $\mathrm{MgCl}_{2}$-method were not statistically significant. However, for Acoela and Retronectida, the Uhlig-method was more efficient than both other methods. We conclude that for a reliable quantitative analysis of Turbellaria 2 different extraction methods are required: one should employ extraction of living material (Uhligmethod) and one extraction of fixed material. For qualitative investigations extraction of living material is recommended.
\end{abstract}

\section{INTRODUCTION}

Comparative data on extraction methods used to estimate density and species composition of turbellarians are scarce (Uhlig, 1964, 1968; Uhlig et al., 1973; Gray and Rieger, 1971; Coull et al., 1977) and data for the different orders do not exist.

In order to investigate extraction efficiencies we performed a comparative quantitative study on 3 different extraction methods: the Barnett-method for fixed material and the 2 well-known extraction methods for living material, the Uhlig- and the $\mathrm{MgCl}_{2}$-method.

\section{MATERIAL AND METHODS}

\section{Sampling methods}

On the sandy beach at De Panne (North Sea coast of Belgium) 36 samples were taken on 29 September 1981, on a nearly horizontal surface with water-saturated sediment. At this time of the year (summer/ autumn), turbellarians from such locations are restricted mainly to the upper sediment layer (own obs.).

A square frame of $36 \times 36 \mathrm{~cm}$ was placed on the bottom. In this frame chords were stretched at intervals of $6 \mathrm{~cm}$ in both directions parallel to the sides of the frame. In this way a grid with 36 square cells was formed. In each cell a sample was taken using a plastic corer covering a surface area of $10 \mathrm{~cm}^{2}$. Samples were taken to a depth of $10 \mathrm{~cm}$. The 36 samples were divided into 3 series of 12 , randomly dispersed over the grid. One series of samples was directly preserved with Formalin ( $4 \%$ ) with Rose Bengal. The other 2 series were not fixed and transported to the laboratory in a cold storage container and extracted after $1 \mathrm{~d}$ to maximum of $6 \mathrm{~d}$ (at a ratio of 2 Uhlig-treated samples and two $\mathrm{MgCl}_{2}$-treated samples a day). Each series was extracted using a different extraction method. Three samples were also taken for sediment analysis. Analysis of the sediment was performed according to Buchanan and Kain (1971).

\section{Extraction of turbellarians}

The first series of unfixed samples was extracted with the sea-water ice method (Uhlig, 1964, 1966, 1968; Uhlig et al., 1973). This extraction method is based on the principle of changing the environment in the sediment so that the animals tend to leave it. It was carried out as follows. Each sample was divided over 2 plastic tubes with a large diameter $(\varnothing=5.6 \mathrm{~cm})$. This 
Table 1. One-way analysis of variance and contrasts; ns not significant $_{i} \cdot p<0.1 ; \cdots p<0.05_{i} \cdots p<0.001$

\begin{tabular}{|l|c|c|c|}
\hline & Whlig-meth. & $\mathrm{MgCl}_{2}$-meth. & Barnett-meth. \\
\hline $\bar{x} \pm$ SD & $72.1 \pm 18.5$ & $56.3 \pm 27.4$ & $167.4 \pm 95.7$ \\
\hline $\begin{array}{l}\text { One-way } \\
\text { analysis of } \\
\text { variance }\end{array}$ & F ratio: $11.62 \quad p:<0.001$ \\
\hline \begin{tabular}{l} 
Contrasts \\
\hline
\end{tabular} & ns & \\
\hline
\end{tabular}

increases the efficiency of the extraction (Uhlig et al., 1973). The bottom of the tube consists of a $125 \mu \mathrm{m}$ mesh sieve. The sediment was covered with a cotton plug on which crushed seawater ice was placed. The tube was fastened over a Petri dish with seawater at room temperature with the sieve just in contact with the surface of the seawater in the dish. The latter is placed in a larger dish to allow the water to overflow. More sea-water ice was added 3 or 4 times resulting in an extraction period of at least $3 \mathrm{~h}$.

From the second series of samples the animals were extracted with the $\mathrm{MgCl}_{2}$-method (Sterrer, 1968; Hulings and Gray, 1971; Crezée, 1976). Each sample was divided over 2 beakers and mixed with a $\mathrm{MgCl}_{2}$ solution isotonic with seawater $( \pm 7 \%)$ in order to narcotize the animals. A volume about 10 times that of the sediment to be extracted was used. After $10 \mathrm{~min}$ the sample was stirred vigorously, and after a few seconds, in which the bulk of the sediment began to settle, the supernatant containing the animals was poured onto a fine mesh sieve $(125 \mu \mathrm{m})$. The filtrate passing the sieve was returned to the beaker with the sediment. The sieve was placed immediately in a Petri dish with clear seawater, in which the animals recovered and swam through the meshes of the sieve into the dish. After about $5 \mathrm{~min}$, the sieve was transferred to a new dish so that the first dish could be examined. The same procedure of transferring the sieve was continued until no further animals were found. Usually 3 transfers were sufficient. Extraction of the sample by stirring and sieving was always repeated 4 times, 3 times with a sieve of $125 \mu \mathrm{m}$ mesh and the last time with a sieve of $63 \mu \mathrm{m}$ (with a smaller mesh-sieve the sieve gets clogged).

The third series with preserved material was extracted with the trough-method or Barnett-method (Barnett, 1968). The aluminum trough was $1 \mathrm{~m}$ long, 3 $\mathrm{cm}$ wide, $2 \mathrm{~cm}$ high and open at one end. The trough was placed in a horizontal position. The samples were spread out in a thin layer along the trough and washed out by slowly running tap water for $20 \mathrm{~min}$. Individuals washed out (and some detritus) were collected on a sieve of $38 \mu \mathrm{m}$.

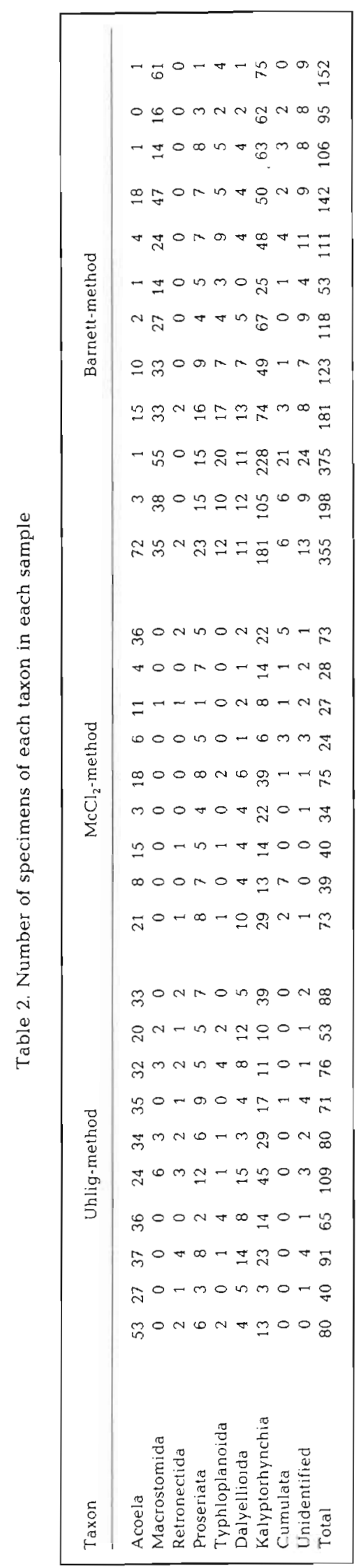


Table 3. Mean values and standard deviations for each taxon extracted by 3 different methods, highest mean of each order and its relative abundance in \% of the total estimated population, both based on their highest means

\begin{tabular}{|c|c|c|c|c|c|}
\hline Taxon & Uhlig-method & $\mathrm{MgCl}_{2}$-method & Barnett-method & Highest mean & $\%$ \\
\hline Acoela & $34.1 \pm 9.3$ & $13.6 \pm 10.5$ & $20.3 \pm 39.5$ & 34 & 18 \\
\hline Macrostomida & $1.4 \pm 2.1$ & $0.1 \pm 0.3$ & $33.1 \pm 15.4$ & 33 & 17 \\
\hline Retronectida & $1.8 \pm 1.1$ & $0.6 \pm 0.7$ & $0.3 \pm 0.8$ & 2 & 1 \\
\hline Proseriata & $6.3 \pm 2.9$ & $5.7 \pm 2.2$ & $9.4 \pm$ & 9 & 5 \\
\hline Typhloplanoida & $1.5 \pm 1.5$ & $0.4 \pm 0.7$ & $8.2 \pm$ & 8 & 4 \\
\hline Dalyellioida & $7.8 \pm 4.4$ & $3.8 \pm 2.9$ & $6.2 \pm 4.5$ & 8 & 4 \\
\hline Kalyptorhynchia & $20.4 \pm 13.5$ & $18.6 \pm 10.6$ & $85.6 \pm 59.6$ & 86 & 44 \\
\hline Cumulata & $0.1 \pm 0.3$ & $2.2 \pm 2.4$ & $4.1 \pm 5.9$ & 4 & 2 \\
\hline Unidentified & $1.9 \pm 1.4$ & $1.2 \pm 1.0$ & $9.9 \pm 4.9$ & 10 & 5 \\
\hline Total & $75.3 \pm 19.6$ & $45.9 \pm 21.5$ & $167.4 \pm 100.0$ & 194 & 100 \\
\hline
\end{tabular}

\section{Counting and identification}

Living animals in the Petri dishes were inspected under the stereomicroscope. Turbellarians were identified to the order-or family-level and picked out. If an animal could not be identified under the stereomicroscope it was examined under a compound microscope. If uncertainty still remained it was recorded as unidentified. The animals were counted in all 36 samples but not identified in 2 samples extracted by the Uhligmethod and in 3 samples treated with the $\mathrm{McCl}_{2}$ method due to shortage of time. All turbellarians extracted with the Barnett-method were picked out under the stereomicroscope and identified under the compound microscope in squeezed preparations (2007 in total).

\section{RESULTS}

The sediment at the sampling station consists of more than $99 \%$ well-sorted fine sand (Md.: 172 to $184 ; \varnothing$ : 0.259 to 0.358 ).

In total 3550 turbellarians were counted. Density in the 36 samples as well as distribution of the 3 series of 12 samples over the experimental square are shown in Fig. 1. Table 1 presents mean density values and standard deviations for the 3 methods. Striking differences exist in mean density values between the 3 methods (Uhlig $\overline{\mathrm{x}}=72.1 ; \mathrm{MgCl}_{2} \overline{\mathrm{x}}=56.5$; Barnett $\overline{\mathrm{x}}=167.4$ ). The results of a one-way analysis of variance (Sokal and Rolf, 1969) and the contrasts are also shown in Table 1. These tests indicate significant differences between the 3 methods $(F=11.62$; df: $(2,33)$; $p<0.001$ ). The contrasts indicate that extraction with the Barnett-method is significantly better than with the Uhlig- and the $\mathrm{MgCl}_{2}$-method.

Table 2 shows the number of identified individuals in each sample, and Table 3 gives mean values and standard deviations for each order after extraction with the different methods. For estimating the mean popu- lation density, we took the highest mean value for each order and calculated the percentual share of each order in the total estimated population (Table 3). The highest number of Acoela, Retronectida and Dalyellioida was found by using the Uhlig-method. For all other orders, the Barnett-method yielded the best results.

A very significant overall difference in the turbellarian fauna extracted with the 3 methods was demonstrated by a MANOVA-analysis (Tatsuoka, 1971) with 9 dependent variables (turbellarian ordines) and 1 independent variable (methods: Uhlig, $\mathrm{MgCl}_{2}$ and Barnett) : Rao's $R=7.3598 ; \quad d f=18,40.0 ; \quad p<0.001$. With this result we are allowed to perform a one-way ANOVA for each turbellarian order. Table 4 shows the results of these analyses and the contrasts (if there was a significant difference). Only for Proseriata and Dalyllioida were no significant differences found. Acoela and Retronectida were significantly better extracted by

Table 4. One-way analysis of variance for each taxon and contrasts between methods for taxons which show significant differences

\begin{tabular}{|c|c|c|c|c|c|}
\hline \multirow[t]{2}{*}{ Taxon } & \multicolumn{2}{|c|}{$\begin{array}{c}\text { One-way analyses } \\
\text { of variance }\end{array}$} & \multicolumn{3}{|c|}{ Contrasts } \\
\hline & $F$ ratio & $p$ & Uhlig-meth. & $\mathrm{MgCl}_{2}$-meth. & Bannett-meth. \\
\hline Acoela & 7.68 & $\star \star \star \star$ & $\quad$ & $\underbrace{}_{\pi \star \star \pi}$ & 5 \\
\hline Macrostomida & 40.41 & $\star \star \star \star$ & as & $\bigsqcup_{\star \pi \star \pi}$ & * \\
\hline Retronectida & 8.09 & $\star \star \star *$ & L*** & $=$ & 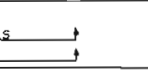 \\
\hline Proseriaca & 2.20 & ns & & & \\
\hline Typhloplatoida & 14.02 & $\star \star \star$ & Lus & $\underbrace{}_{\star \pi \pi}$ & 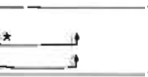 \\
\hline Dalyelloida & 2.31 & ns & & & \\
\hline Kalyptorhyachia & $10.8 \epsilon$ & $\star * *$ & as & $\sum_{\star \star \star \star}$ & ¿ \\
\hline Cumulata & 3.00 & * & ns & 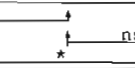 & 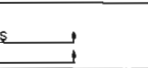 \\
\hline Unidentified & 24.67 & 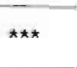 & ns & $t_{\star \star \star \star} \quad \star$ & 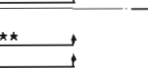 \\
\hline
\end{tabular}


Table 5. Species occurring in the experimental square

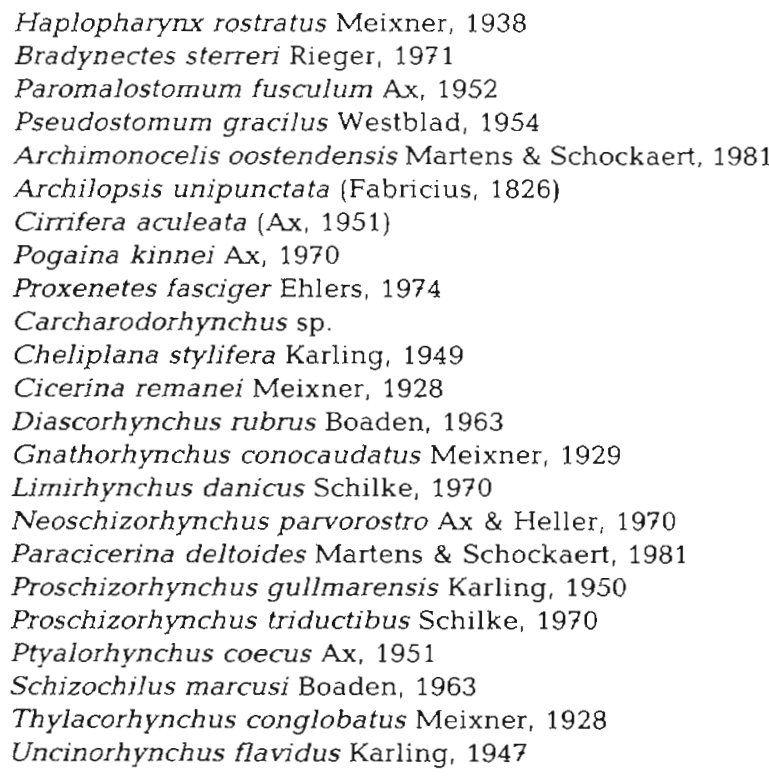

the Uhlig-method than by the other 2 methods. With this method Acoela were also extracted much more rapidly (within $15 \mathrm{~min}$ ) than Kalyptorhynchia. For Macrostomida, Typhloplanoida and Kalyptorhynchia the Barnett-method was significantly better than the methods for extraction of living animals. This method is also more efficient for the extraction of Cumulata when compared to the Uhlig-method. On the other hand, the number of unidentified specimens (order level) is higher after the extraction of a preserved sample but less than $10 \%$ of the total number.

In total, more than 30 species were present, 23 of them were identified (Table 5). Acoela and Retronectida were not identified. The Acoela were represented by more than 5 species, the Retronectida by 1 . One of the Acoela species was large and could easily be recognized. The high number of 72 Acoela in 1 sample extracted with the Barnett-method (Table 2) was due to the presence of this species. From the 3 Macrostomida species (Haplopharynx is included with the Macrostomida) only Paromalostomum fusculum was found in high numbers. More than $95 \%$ of the Macrostomida extracted with the Barnett-method were Paromalostomum fusculum. Only 1 species of Cumulata was found, Pseudostomum gracilis, which has an epibenthic way of life (own obs.).

\section{DISCUSSION}

In contrast to data from literature, the present results show that the Uhlig-method and the $\mathrm{MgCl}_{2}$-method

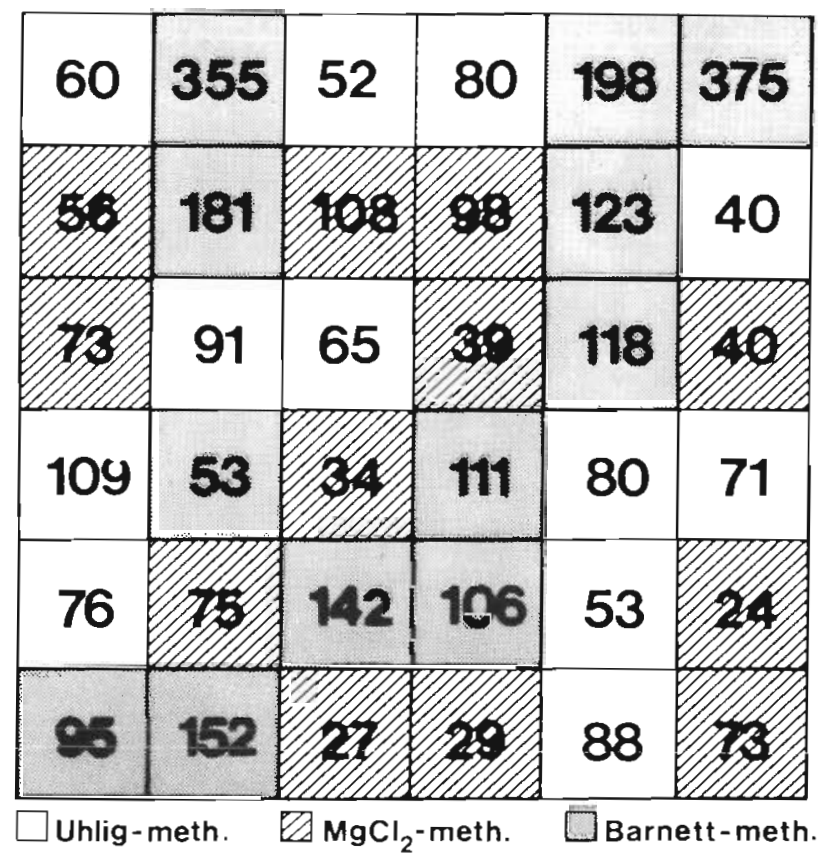

Fig. 1. Distribution of 3 series of 12 samples over the experimental square with the number of turbellarians found in each sample

have an extraction efficiency of less than $50 \%$. This discrepancy is due to the fact that no statistical comparison between extraction methods for living material and a method using preserved material has ever been made for turbellarians.

The first study concerning the efficiency of extraction of turbellarians with sea-water ice was done by Uhlig (1964). He placed 50 turbellarians in a sterile sediment. After 1 h he was able to extract 38 turbellarians $(=76 \%)$. However, the 50 turbellarians used in his experiment had been extracted before with the same method. So a biased sample was obtained that did not necessarily reflect the true composition of the fauna but consisted of already selected animals that are easily extracted with the method. Uhlig (1968, p. 229) also discussed some data of Zinn, who used 2 different methods in succession on the same sample, i.e. a 'mechanical' extraction method (decantationmethod?) and the sea-water ice method. Two samples were extracted, and for the second sample the sequence of extraction was inversed as compared to the first sample. In the first sample 23 (mechanical) and 49 (Uhlig) turbellarians were found respectively, while in the second sample 118 (Uhlig) and 21 (mechanical) turbellarians were found. Unfortunately, this experiment was not repeated, and the 2 samples appear to have been very different. Moreover, when these results are analysed carefully it can be calculated that not more than $25 \%$ of the fauna is extracted with the mechanical method, and not more than about $58 \%$ 
with the Uhlig-method. We agree with Uhlig that the efficiency of the sea-water ice method is more than $90 \%$ higher than the mechanical separation (Zinn), but it is also clear that the efficiency of the Uhlig-method is less than 75 to $90 \%$ as stated by Hulings and Gray (1971). Uhlig et al. (1973) compared different extraction methods for meiofauna. They concluded that the decantation method of Elmgren and the elutriation method of Mcintyre (both on preserved material; see Uhlig et al., 1973) have the same efficiency as the Uhlig-method. In fact, they showed that decantation was even better. They also demonstrated that the efficiency of the Uhlig-method depends on diameter of the extraction tube, and it is also clear that it depends on the amount of sediment extracted, the extraction time and the mesh size of the sieve, which makes this method unreliable for comparative studies.

Barnett (1968) described a new extraction method (for Harpacticoidea) with better results than former extraction methods. Heip (1971, 1976, pers. comm.) found that the method gives better results for most meiofauna taxa in fine sand and sand with detritus or mud than any other method and can have an efficiency up to $100 \%$. Also from our results we can conclude that the Barnett-method has a higher efficiency than the Uhlig- or $\mathrm{MgCl}_{2}$-method, but the efficiency does not reach $100 \%$, at least not for all turbellarians.

Differences in efficiency of the methods used can be understood in part by the biology of the different turbellarian groups. Acoela are very soft and small turbellarians. This can explain why they are not extracted efficiently with the $\mathrm{MgCl}_{2}$-method: they are washed through the sieve, and damaged when the sediment is vigorously stirred. Sorting and counting Acoela after extraction with the Barnett-method is difficult since they look like small oval lumps after fixation and can easily be mistaken for detritus particles or for ciliates. On the other hand, Acoela are fast and flee quickly (mostly downwards) in a stress situation. These characteristics explain the fast and efficient extraction with the Uhlig-method.

The Barnett-method extracts Kalyptorhynchia, Typhloplanoida and Macrostomida with a greater efficiency than the other methods. These turbellarians are large and can easily be recognized. In reaction to a stress situation they use adhesive glands and stick to sand grains. This can explain the poor results with the Uhlig-method as well as with the $\mathrm{MgCl}_{2}$-method, since anaesthesia with $\mathrm{MgCl}_{2}$ is not total.

pseudostoma gracilis was the only representative of the Cumulata found in our samples. From our own observations we know that this species is epibenthic and so this animal probably dislikes to crawl through a sieve. Using the $\mathrm{MgCl}_{2}$-method this species was indeed mostly found in the last Petri dish examined.
In most ecological studies where the Uhlig-method was used, the Proseriata (Sopott, 1973) or the Acoela (Gray and Rieger, 1971; Faubel, 1976), or both (Martens and Schockaert, 1981), were found to be the dominant turbellarian taxon. In the present study, the Uhlig-method also revealed a dominance of Acoela. However, using the total information available on the 3 methods, we conclude that Kalyptorhynchia are the most abundant group. Therefore, Kalyptorhynchia may have been quantitatively underestimated in earlier studies as a result of the extraction method used, or our samples may have been relatively rich in Kalyptorhynchia. Our results indicate that the number of Kalyptorhynchia is underestimated when the Uhlig- or the $\mathrm{MgCl}_{2}$-method is used, at least in the sediment we studied. We found indeed that the fauna extracted with the Uhlig-method contained $26 \%(\bar{x}=20)$ of Kalyptorhynchia, $41 \%(\overline{\mathrm{x}}=19)$ after extraction with $\mathrm{MgCl}_{2}-$ method and $51 \%(\bar{x}=86)$ after extraction with the Barnett-method. Ehlers (1973) and Sopott (1973) report that only $10 \%$ of the turbellarian fauna were Kalyptorhynchia (after extraction with sea-water ice) while Gray and Rieger (1971) found 7 to $30 \%$ after extraction with $\mathrm{MgCl}_{2}$-method followed by a second extraction by decantation after rinsing the sediment with ethylalcohol $(10 \%)$. However, all these authors used mediumto-coarse sand, and it is generally accepted (Uhlig et al., 1973) that the Uhlig-method yields better results with a coarse sediment than with fine sand. So the underestimation of the number of the Kalyptorhynchia may be less pronounced than our tables would suggest. On the other hand, Kalyptorhynchia may be more abundant in coarse than in fine sand, as we are strongly inclined to believe from our experience.

\section{CONCLUSION}

None of the methods known so far are reliable for quantitative studies of turbellarians. Extraction of preserved samples yields the best results for the majority of turbellarian orders but gives an underestimation for small and delicate animals such as most Acoela. For this group the Uhlig-method is recommended. Both methods must be combined: a sample extracted first with sea-water ice is fixed and extracted a second time, or both methods are applied to 2 samples from the same locality. The extraction of preserved material can be performed with the Barnett-method; where the sediment consists of coarse sand the decantation method may be satisfactory. A difficulty with preserved material is that only turbellarians with hard structures in their genital organs can be identified and that previous knowledge of the fauna studied is required. For the 
qualitative analysis of the fauna, the $\mathrm{MgCl}_{2}$-method or the Uhlig-method are the obvious methods to be used.

Acknowledgements. I wish to thank Rudy Herman and Dirk Van Gansbeke for sediment analyses and extractions with the Barnett-method at the Laboratorium voor Morfologie en Systematiek der Dieren of the State University of Ghent. I also thank Dr. H. Verhaeghe for help with statistical analysis, Professor Dr. E. R. Schockaert, Dr. C. Heip (State University of Ghent) and Luc Snoecks for enlightening discussions and critical reading of the manuscript, and Professor Dr M. Van Poucke for revising my English. Technical assistance of Mrs. Ievens and Miss Heymans is very much appreciated.

\section{LITERATURE CITED}

Barnett, P. R. O. (1968). Distribution and ecology of harpacticoid, copepods of an intertidal mudflat. Int. Revue ges. Hydrobiol. 53: 177-209

Buchanan, J. B., Kain, J. M. (1971). Measurement of the physical and chemical environment. In: Holm, N. A. McIntyre, A. D. (ed.) IBP Handbook $N^{\circ} 16$. Blackwell Scientific publication, Oxford, p. 30-58

Coull, B. C., Ellison, R. L., Fleeger, J. W., Higgins, R. P., Hope, W. D., Hummon, W. D., Rieder, R. M., Sterrer, W. S., Thiel, H., Tietjen, J. H. (1977). Quantitative estimates of meiofauna from the deep sea off North Carolina, USA. Mar. Biol. 39: 233-240

Crezée, M. (1976). Solenofilomorphidae (Acoelá), major component of a new turbellarian association in the sulfide system. Int. Revue ges. Hydrobiol. 61: 105-129

Ehlers, U. (1973). Zur Populationsstruktur interstitieller Typhloplanoida und Dalyellioida (Turbellaria, Neorhabdocoela). Mikrofauna Meeresboden 19: 1-105
Faubel, A. (1976). Populationsdynamik und Lebenszyklen interstitieller Acoela und Macrostomida (Turbellaria). Mikrofauna Meeresboden 56: 1-107

Gray, J. S., Rieger, R. M. (1971). A quantitative study of the meiofauna of an exposed sandy beach, at Robin Hood's Bay, Yorkshire. J. mar. biol. Ass. U.K. 51: 1-19

Heip, C. (1971). The succession of benthic micrometazoans in a brackisch water habitat. Biol. Jaarb. 39: 191-196

Heip, C. (1976). The life-cycle of Cyprideis torosa (Crustacea, Ostracoda). Oecologia 24: 229-245

Hulings, N. C., Gray, J. S. (1971). A manual for the study of meiofauna. Smithson. Contr. Zool. 78: 1-83

Martens, P. M., Schockaert, E. R. (1981). Sand dwelling Turbellaria from the Netherlands Delta area. In: Schockaert, E. R., Ball, I. R. (ed.) The biology of the Turbellaria. Hydrobiologia 84: 113-127

Sokal, R. P., Rohlf, F. T. (1969). Biometry, Freeman, San Francisco

Sopott, B. (1973). Jahreszeitliche Verteilung und Lebenszyklen der Proseriata (Turbellaria) eines Sandstrandes der Nordseeinsel Sylt. Mikrofauna Meeresboden 15: 1-106

Sterrer, W. (1968). Beiträge zur Kenntnis der Gnathostomulida. I. Anatomie und Morphologie des Genus Pterognathia Sterrer. Ark. Zool. 22: 1-125

Tatsuoka, M. M. (1971). Multivariate analyses: techniques for educational and psychological research. Wiley, New York

Uhlig, G. (1964). Eine einfache Methode zur Extraction der vagilen, mesopsammalen Mikrofauna. Helgoländer wiss. Meeresunters. 11: 178-185

Uhlig, G. (1966). Untersuchungen zur Extraction der vagilen Mikrofauna aus marinen Sedimenten. Zool. Anz. 29: 151-157

Uhlig, G. (1968). Quantitative methods in the study of interstitial fauna. Trans. Am. Microsc. Soc. 87: 226-232

Uhlig, G., Thiel, H., Gray, J. S. (1973). The quantitative separation of meiofauna. A comparison of methods. Helgoländer wiss. Meeresunters. 25: 173-195 